\title{
Reduction of INTEC Analytical Radioactive Liquid Wastes
}

\author{
V. J. Johnson \\ J. S. Hu
}

A. G. Chambers

LOCKHEEDMATTIN 


\title{
Reduction of INTEC Analytical Radioactive Liquid Wastes
}

\author{
V. Jim Johnson \\ Jian S. Hu \\ Andrea G.Chambers
}

Published June 1999

Idaho National Engineering and Environmental Laboratory High Level Waste Program Department Lockheed Martin Idaho Technologies Company, Inc. Idaho Falls, Idaho 83415

\author{
Prepared for the \\ U.S. Department of Energy \\ Assistant Secretary for \\ Environmental Management \\ Under DOE Idaho Operations Office \\ Contract DE-AC07-94ID13223
}




\section{ABSTRACT}

This report details the evaluation of the reduction in radioactive liquid waste from the analytical laboratories sent to the Process Effluent Waste system (deep tanks). The contributors are the Analytical Laboratories Department (ALD), the Waste Operations Department, the laboratories at CPP-637, and natural run off. Other labs were contacted to learn of methods used and if any new technologies had emerged. A waste generation database was made from the current methods in use in the ALD. From this database, methods were targeted to reduce waste. Individuals were contacted on ways to reduce waste. The results are: a new method generating much less waste, several methods being handled differently, some cleaning processes being changed to reduce waste, and changes to reduce chemicals to waste. 


\section{SUMMARY}

This report covers the waste reduction efforts to reduce analytical waste to the deep tanks (WG-100, WG-101, WH-100, and WH-101). Efforts were limited to the analytical chemistry labs, since they were the major contributors. Analytical Chemistry had several potential ways that could reduce waste generation.

A database was developed on the 1997/1998 analytical methods used. Emphasis was put on the year 1998. Waste was categorized based on method, sample waste and cleanup waste. The methods with the greatest waste generation were looked at for ways to reduce or change to accomplish a reduction in waste. These were looked at because they would have the greatest impact on waste reduction.

Other laboratories were contacted to discover their waste reduction efforts. These reduction efforts by other labs were compared with the INTEC labs to see if anything was usable.

Recommendations were made on how to make more reductions. Most of these are in the process of being implemented. 


\section{ACKNOWLEDGEMENTS}

The authors wish to acknowledge the assistance of Rick Demmer, Kip Archibald, Mark Argyle, Lance Lauerhass, Joe Henscheid, and the Analytical Chemistry Department in developing this report. 


\section{CONTENTS}

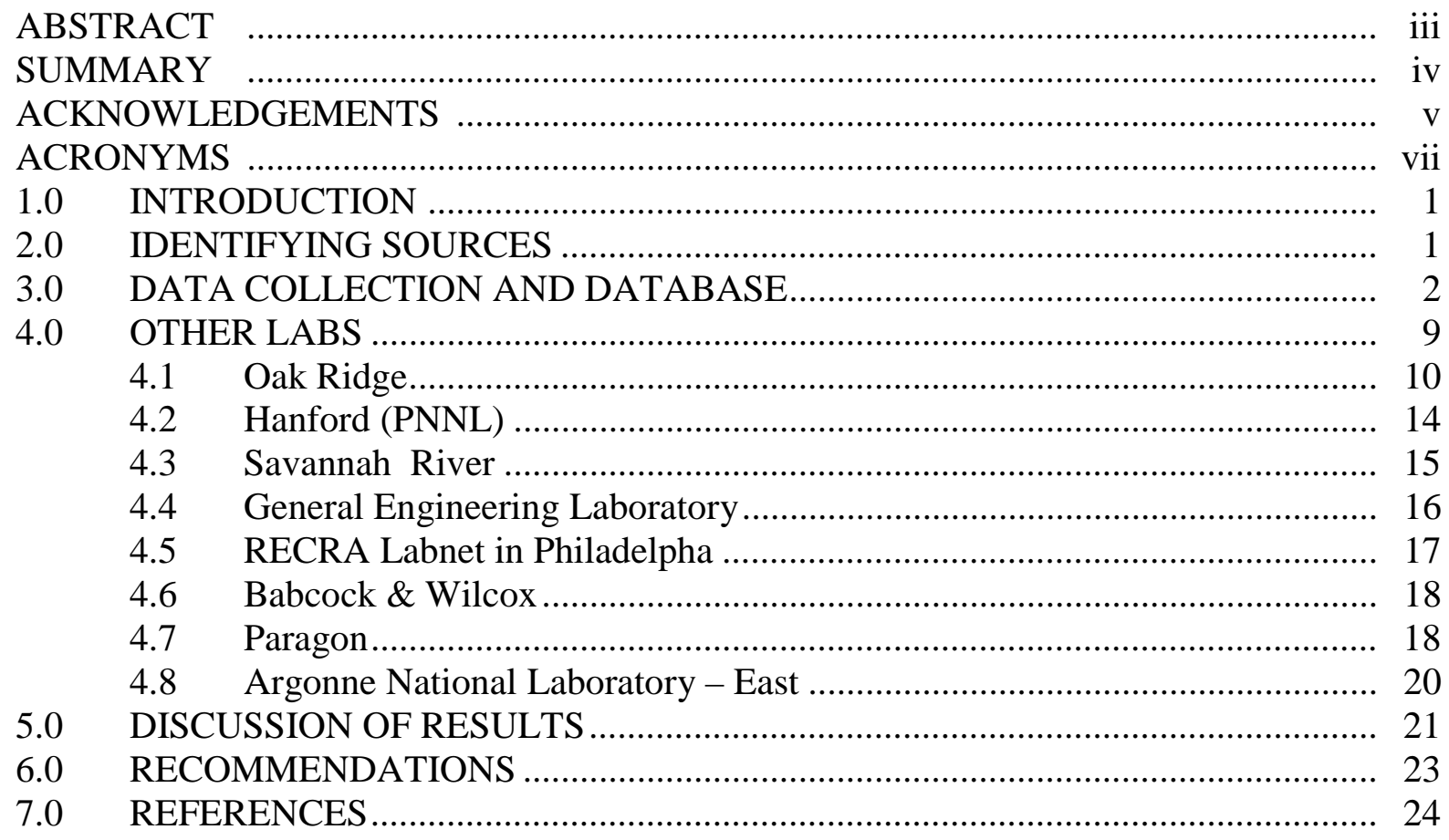

\section{FIGURES}

1. The distribution of ALD waste generated by methods in $1998 \ldots \ldots \ldots \ldots \ldots \ldots \ldots \ldots \ldots \ldots \ldots . . . \quad 5$

2. The liquid waste generated by the top five methods in 1997 and 1998 .................. 8

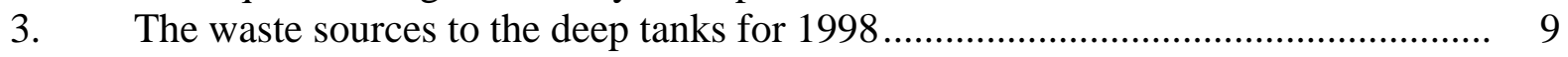

\section{TABLES}

1. The number of times the methods were run and the volumes of waste generated by running the methods (all volumes in $\mathrm{mL}$ ) ............................................................ 3

2. The top 10 liquid waste generators in year 1998, gallons/run ................................ 6

3. The 10 most frequently run methods in year 1998............................................... 6

4. The top 10 liquid waste generators in year 1998, gallons/year ................................. 7

5. The details of the five top liquid waste generators in year 1998............................. 8 


\section{ACRONYMS}

$\begin{array}{ll}\text { AA } & \text { atomic absorption } \\ \text { ALD } & \text { Analytical Laboratories Department } \\ \text { Am } & \text { americium } \\ \text { Am-241 } & \text { americium - 241 (isotopic weight) } \\ \text { ANL-E } & \text { Argonne National Laboratory - East } \\ \text { APSU } & \text { Aqueous Phase Separation Unit } \\ \text { Ba } & \text { barium } \\ \text { C-14 } & \text { carbon - 14 (isotopic weight) } \\ \text { Co-60 } & \text { cobalt - 60 (isotopic weight) } \\ \text { CPP } & \text { Chemical Processing Plant } \\ \text { Cr } & \text { chromium } \\ \text { DOE } & \text { Department of Energy } \\ \text { EPA } & \text { Environmental Protection Agency } \\ \text { GC/MS } & \text { Gas Chromatograph / Mass Spectrometer } \\ \text { H-3 } & \text { tritium } \\ \text { HNO3 } & \text { nitric acid } \\ \text { HCl } & \text { hydrochloric acid } \\ \text { INTEC } & \text { Idaho Nuclear Technology and Engineering Center } \\ \text { ICP } & \text { inductively coupled plasma } \\ \text { ICP-MS } & \text { Inductively Coupled Plasma - Mass Spectrometer } \\ \text { LMITCO } & \text { Lockheed Martin Idaho Technologies Company } \\ \text { MAE } & \text { Microwave Assisted Extraction } \\ \text { Np } & \text { neptunium } \\ \text { PCB } & \text { Poly Chlorinated Biphenyl } \\ \text { PEW } & \text { Process Effluent Waste } \\ \text { PEWE } & \text { Process Effluent Waste Evaporator } \\ \text { PNNL } & \text { Pacific Northwest National Labs } \\ \text { Pu-238/239 } & \text { plutonium -238/239 (isotopic weight) } \\ \text { RAL } & \text { remote analytical laboratories } \\ \text { RCRA } & \text { Resource and Conservation Recovery Act } \\ \text { RLWR } & \text { Radioactive Liquid Waste Reduction group } \\ \text { Sr-90 } & \text { strontium - 90 (isotopic weight) } \\ \text { SVOC } & \text { Semi-Volatile Organic Carbon } \\ \text { SW-846 } & \text { Statement of Work - Document Number } 846 \\ \text { Th } & \text { thorium } \\ \text { TIMS } & \text { Thermal Ionization Mass Spectrometer } \\ \text { TKN } & \text { total kjeldahl nitrogen } \\ \text { U } & \text { uranium } \\ & \end{array}$




\section{Reduction of INTEC Analytical Radioactive Liquid Wastes}

\subsection{INTRODUCTION}

The Radioactive Liquid Waste Reduction Group (RLWR) has the task of reducing radioactive liquid waste to the Process Effluent Waste Evaporator (PEWE) system and more specifically the waste to the Idaho Nuclear Technology and Engineering Center (INTEC) deep tanks system. This task is accomplished by identifying the contributors, reviewing processes that generate waste, looking at other sites for new ideas and technologies, and evaluating new ways to reduce waste.

The Process Effluent Waste (PEW) deep tanks (WG-100, WH-101, WG-101 and WH100) have been used for about 50 years for wastes from the chemical processing plant and analytical laboratories. Identifying the waste generators to the deep tanks is not a straightforward process because so many of the pipes are interconnected and identification of where the waste is generated is nearly impossible. Waste operations personnel could only say that the analytical laboratories (including the CPP-637 laboratories), waste operations, and annual run off were the contributors. Each of these areas is examined for ways to reduce liquid waste generation.

An additional concern for laboratory waste generation is the large number of waste characterizations that will be required over the coming years to accomplish the company's goals in environmental restoration and waste management. The secondary waste generated from the analytical procedures used for such characterizations is a significant source of new PEW waste. Reducing the volume of the secondary waste and the costs associated with its handling and disposal are big steps in meeting various milestones, consent orders, and requirements of the Site Treatment Plan.

\subsection{IDENTIFYING SOURCES}

Waste operations personnel identified three sources of waste that contributed to the deep tanks (24320 gallons for 1998). First is the 275 gallons of 13 molar nitric acid added to each deep tank to insure that all uranium stays in solution (Technical Standard 42 A6, 2A3). This represents 2200 gallons of nitric acid added in 1998 ( 8 batches). The second is the rinsing and cleanup of chemical deliveries to the plant. Tanker trucks, trailers, and hoses must be cleaned with water after delivering chemicals to INTEC. This represents about 1000 gallons in a year. The third is loop seals in the drains. About two and one half gallons of water a week is placed in each of eight loop seals. This represents another 1000 gallons to the deep tanks. The above volumes added together are a total of 4200 gallons to the deep tanks in a year. This is a baseline amount that is needed just to keep up with the waste being generated. 
Storm water also contributes a great deal to the deep tanks. This varies with the snow pack and moisture received in any given year. The 1000 gallons is an approximation by waste operations for the year 1998. The rest of the volume (19120 gallons) is attributed to Analytical Laboratories Department (ALD) laboratory waste and a very small volume from CPP-637 laboratories (1 gallon for 1998).

\subsection{DATA COLLECTION AND DATABASE}

The first phase in the evaluation of the INTEC Analytical Laboratory liquid waste, was to identify the liquid waste generated by each analytical method, establish a database as the benchmark, and identify the top liquid waste generators. A list of methods and the number of times each was performed by the different analysts in 1998 was obtained from the ALD computer group. This data was compiled in a database. The methods were split into three groups: the 2000 series (radiochemistry) / 3000 series (spectrochemistry), the 7000 series Remote Analytical Laboratory (RAL), and the 8000series (special analysis) / 9000 series (organic chemistry). Each of these series was given to one of the authors to obtain data on the methods. A survey was sent out to the various analysts to identify the wastes produced from each analytical method. This means of gathering data proved to be very inadequate at best because very few surveys were returned. Personal visits, record searching, and procedure reviewing were used to determine the chemicals the analysts added at every step of the procedure and to calculate the actual liquid waste generated by each method. For some complicated methods, the authors observed the analysts working in the laboratory to gather the first-hand information. Microsoft "Access" was used as the database to compile and manipulate the data. This database includes the data on the analytical methods, personnel information, and the number of times the analysts ran each method, the chemicals used, and the calculated actual volume liquid waste generated by each method were also entered into the database. The technical information includes the method number, method title, equipment used, elements analyzed, etc. The personnel information includes the key analyst of the method, his supervisor, location of the laboratory, etc. The liquid waste generation information includes the sample liquid waste generated and chemicals added per each analysis, the total number of analyses conducted per year, and etc. The liquid waste is separated into four categories: sample, sample preparation, rinse, and other. "Sample" is the amount of original sample requested by the analysts from the customers. "Sample preparation" is the summation of all the chemicals added in the sample preparation. "Rinse" is the amount of water used in rinsing the glassware after the analysis. "Others" are all the other waste sources that are not covered in the above categories.

By extracting data from the database, a series of tables were prepared to identify the most frequently run methods, the top liquid waste generators per analytical run, and the top liquid waste generators per year. It shows the total and per-run liquid waste generated by all methods in year 1998, a report analyzing the distribution of liquid waste among the four sources in year 1998, and a report identifing the top 10 liquid waste generators in year 1998. 
Table 1 gives the method number, the number of times the analysis was performed (runs), and the liquid wastes generated. From this table the total liquid waste generated by the analytical laboratory during 1998 was 8,551 gallons.

Table 1. The number of times the methods were run and the volumes of waste generated by running the methods (all volumes in $\mathrm{mL}$ ).

\begin{tabular}{|c|c|c|c|c|c|c|}
\hline Method \# & Runs & Sample & Sample Prep. & Rinse & Others & Subtotal \\
\hline 2000 & 1 & & 0 & 4160000 & 76000 & 4236000 \\
\hline 2005 & 76 & & 0 & 0 & 11400 & 11400 \\
\hline 2051 & 2 & & 0 & 0 & 600 & 600 \\
\hline 2171 & 68 & & 204 & 340000 & 10200 & 350404 \\
\hline 2806 & 81 & 8100 & 72900 & 0 & 0 & 81000 \\
\hline 2807 & 207 & 3105 & 33534 & 0 & 0 & 36639 \\
\hline 2808 & 11 & 550 & 803 & 33 & 5720 & 7106 \\
\hline 2900 & 1294 & 19410 & 0 & 0 & 0 & 19410 \\
\hline 3011 & 435 & 13050 & 6525 & 0 & 26100 & 45675 \\
\hline 3200 & 5 & 150 & 750 & 1500 & 700 & 3100 \\
\hline 3201 & 154 & 4620 & 23100 & 46200 & 21560 & 95480 \\
\hline 3202 & 227 & 6810 & 34050 & 68100 & 31780 & 140740 \\
\hline 3204 & 50 & 1500 & 7500 & 15000 & 7000 & 31000 \\
\hline 3381 & 882 & 441000 & 29547 & 894348 & 16758 & 1381653 \\
\hline 3384 & 6 & 480 & 66 & 144 & 5010 & 5700 \\
\hline 3431 & 24 & 240 & 888 & 0 & 600 & 1728 \\
\hline 3536 & 2 & 30 & 42 & 14 & 100 & 186 \\
\hline 3539 & 37 & 555 & 777 & 259 & 1850 & 3441 \\
\hline 3450 & 492 & 0 & 0 & 21648 & 0 & 21648 \\
\hline 3900 & 4 & 120 & 600 & 1200 & 560 & 2480 \\
\hline 3948 & 56 & 1680 & 8736 & 16692816 & 2464 & 16705696 \\
\hline 3993 & 2550 & 1275000 & 1275000 & 0 & 0 & 2550000 \\
\hline 3993 & 2550 & 1275000 & 1275000 & 0 & 0 & 2550000 \\
\hline 4900 & 18 & & 0.09 & 0 & 0 & 0.09 \\
\hline 7000 & 4043 & & 242580 & 0 & 1617200 & 1859780 \\
\hline 7012 & 311 & 62.2 & 7775 & 7775 & 15550 & 31162.2 \\
\hline 7016 & 165 & 4125 & 0 & 4125 & 0 & 8250 \\
\hline 7017 & 636 & 15900 & 0 & 15900 & 0 & 31800 \\
\hline
\end{tabular}

Table 1. (continued). 


\begin{tabular}{|c|c|c|c|c|c|c|}
\hline Method \# & Runs & Sample & Sample Prep. & Rinse & Others & Subtotal \\
\hline 7061 & 45 & 1125 & 427.5 & 1125 & 0 & 2677.5 \\
\hline 7071 & 188 & 188 & 26320 & 37600 & 0 & 64108 \\
\hline 7074 & 330 & 33 & 29700 & 0 & 0 & 29733 \\
\hline 7092 & 382 & 7640 & 7640 & 0 & 19100 & 34380 \\
\hline 7093 & 536 & 536 & 10720 & 0 & 26800 & 38056 \\
\hline 7100 & 795 & 159 & 0 & 0 & 39750 & 39909 \\
\hline 7168 & 166 & & 14940 & 0 & 0 & 14940 \\
\hline 7171 & 769 & 153.8 & 30760 & 0 & 57675 & 88588.8 \\
\hline 7920 & 251 & 50.2 & 2033.1 & 0 & 0 & 2083.3 \\
\hline 7929 & 25 & 25 & 627.5 & 0 & 0 & 652.5 \\
\hline 7961 & 52 & & 7800 & 0 & 0 & 7800 \\
\hline 7962 & 416 & 41600 & 0 & 31200 & 0 & 72800 \\
\hline 7970 & 389 & & 19450 & 58350 & 0 & 77800 \\
\hline 7972 & 168 & 1680 & 7392 & 0 & 0 & 9072 \\
\hline 7975 & 43 & & 0 & 0 & 51600 & 51600 \\
\hline 7981 & 541 & 1623 & 1623 & 0 & 32460 & 35706 \\
\hline 7985 & 10 & & 0 & 0 & 1070 & 1070 \\
\hline 7989 & 5 & 0 & 0 & 1000 & 1000 & \\
\hline 8060 & 531 & 21240 & 22302 & 26550 & 0 & 70092 \\
\hline 8069 & 14 & 0 & 0 & 0 & 0 & 0 \\
\hline 8075 & 8 & 4000 & 12000 & 240000 & 0 & 256000 \\
\hline 8076 & 66 & 33000 & 99000 & 1980000 & 0 & 2112000 \\
\hline 8104 & 98 & 9800 & 14700 & 49000 & 12250 & 85750 \\
\hline 8202 & 336 & 33600 & 57204 & 168000 & 16800 & 275604 \\
\hline 8203 & 252 & 25200 & 42890.4 & 126000 & 12600 & 206690.4 \\
\hline 8204 & 389 & 38900 & 66519 & 194500 & 19450 & 319369 \\
\hline 8205 & 297 & 29700 & 50519.7 & 148500 & 14850 & 243569.7 \\
\hline 8206 & 237 & 23700 & 40313.7 & 118500 & 11850 & 194363.7 \\
\hline 8302 & 30 & 6000 & 9000 & 15000 & 7500 & 37500 \\
\hline 8303 & 17 & 3400 & 5100 & 8500 & 4250 & 21250 \\
\hline 8305 & 12 & 2400 & 3600 & 6000 & 3000 & 15000 \\
\hline 8909 & 67 & & 3350 & 10050 & 0 & 13400 \\
\hline
\end{tabular}

Table 1. (continued). 


\begin{tabular}{ccccccc}
\hline Method \# & Runs & Sample & Sample Prep. & Rinse & Others & Subtotal \\
\hline 8974 & 445 & 17800 & 0 & 66750 & 111250 & 195800 \\
8978 & 1 & 40 & 0 & 150 & 250 & 440 \\
8979 & 18 & 720 & 0 & 2700 & 4500 & 7920 \\
8998 & 130 & & 13000 & 0 & 5200 & 18200 \\
9080 & 11 & & 0 & 550 & 0 & 550 \\
9081 & 27 & 0 & 0 & 1350 & 0 & 1350 \\
9260 & 105 & 1575 & 0 & 3150 & 0 & 4725 \\
9270 & 66 & 33000 & 3960 & 1980 & 0 & 38940 \\
9354 & 20 & 300 & 0 & 600 & 0 & 900 \\
9990 & 12 & 6000 & 720 & 360 & 0 & 7080 \\
\hline
\end{tabular}

Total runs 20,234

\begin{tabular}{cccccc}
$\mathrm{mL}$ & $2,141,675$ & $2,348,989$ & $25,572,140$ & $2,304,357$ & $\mathbf{3 2 , 3 6 7 , 1 6 1}$ \\
gallons & 566 & 621 & 6,756 & 609 & $\mathbf{8 , 5 5 1}$ \\
$\%$ & $6.62 \%$ & $7.26 \%$ & $79.01 \%$ & $7.12 \%$ & $\mathbf{1 0 0 . 0 0 \%}$ \\
\hline
\end{tabular}

In Figure 1 it can be seen that the most liquid waste was generated from glassware wash and rinse (about $80 \%$ ). The other three sources accounted for only $7 \%$ each of the total waste generated by the methods.

Figure 1. The distribution of ALD waste generated by methods in 1998.

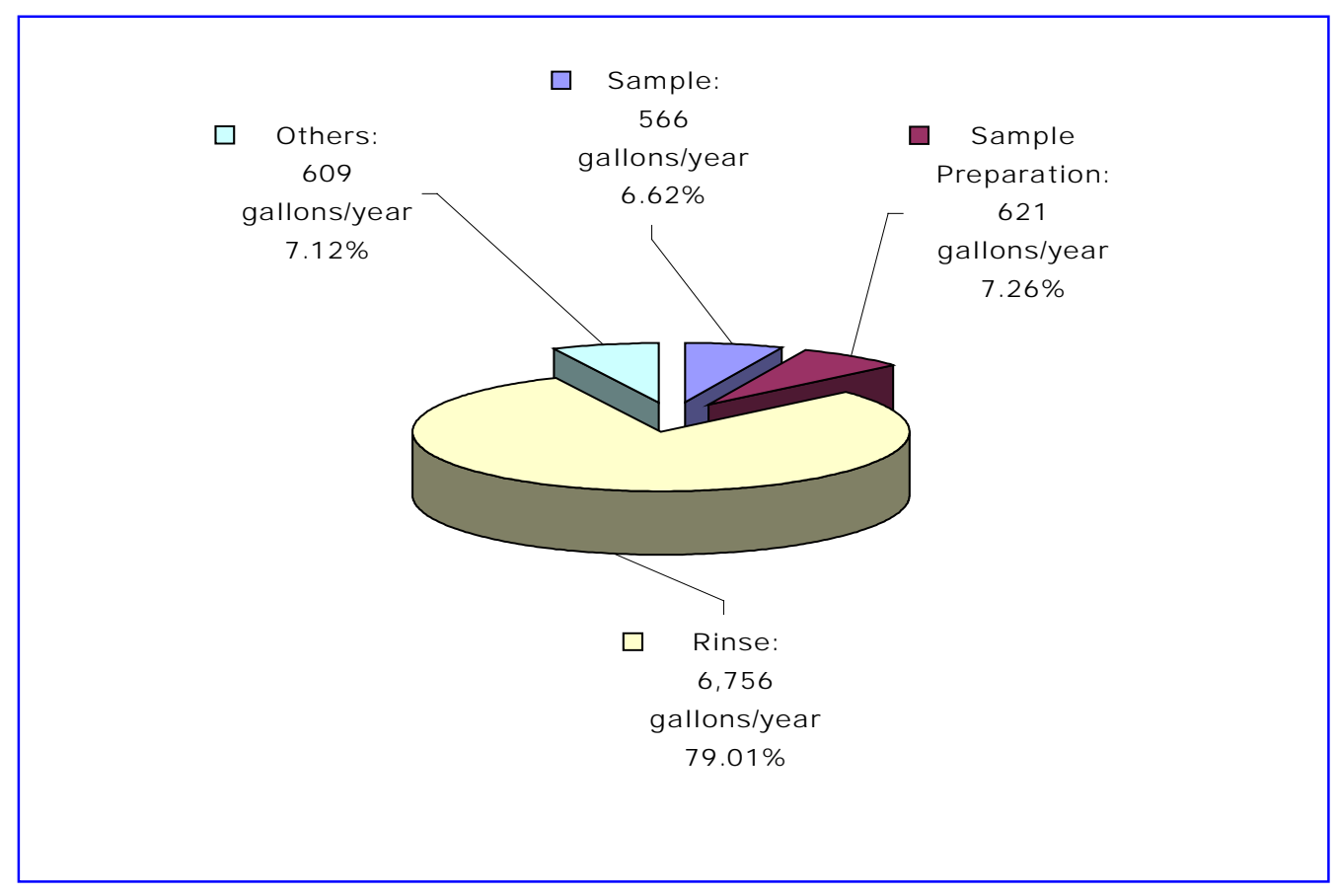


Two ways can be used to define the ten top liquid waste generators: (1) based on the liquid waste generated per analytical run, (2) based on the total liquid waste generated per year. The top 10 liquid-waste generators based on gallons/run are listed in Table 2. The number one liquid waste generator was method 3948. It generated 78.82 gallons of liquid waste per run, which is almost ten times higher than that of the second method on the list. Also, on this list, there are only five methods that generated more than one gallon of liquid waste per run.

Table 2. The top 10 liquid waste generators in year 1998, gallons/run.

\begin{tabular}{clc}
\hline \hline Method \# & \multicolumn{1}{c}{ Method Name } & LW, gallon/run \\
\hline 3948 & Pu-Filt-1 & 78.82 \\
8075 & TKN-color-1 & 8.45 \\
8076 & TKN-color-1 & 8.45 \\
\hline 2171 & X-ray Fluorescence - Cl & 1.36 \\
2350 & GFA-AA-1 & 1.35 \\
3381 & SR-Radio-1 & 0.41 \\
8107 & Anions-EPA-1 & 0.33 \\
8302 & Anions-EPA-1 & 0.33 \\
8303 & Anions-EPA-1 & 0.33 \\
8305 & Anions-EPA-1 & 0.33 \\
\hline \hline
\end{tabular}

Gallons/year is the multiplication of the runs/year and gallons/run. The authors determined that, the top liquid waste generators identified by their total liquid wastes generated per year is more representative. The 10 most frequently run methods in the year 1998 are listed in Table 3. The top two on the table are method 3993 (run 2,550 times in year 1998) and method 2900 (run 1,294 times in year 1998).

Table 3. The 10 most frequently run methods in year 1998.

\begin{tabular}{clc}
\hline \hline Method \# & \multicolumn{1}{c}{ Method Name } & Runs \\
\hline 3993 & Gamma Spectrometry & 2,550 \\
2900 & Metal-ICP-RCRA & 1,294 \\
3381 & SR-Radio-1 & 882 \\
7100 & Metals-ICP-1 & 795 \\
7171 & Cl-Vol-1 & 769 \\
7802 & Hg-AA-1 & 720 \\
7017 & pH-Pot-1 & 636 \\
7981 & SP-Gr-3 & 541 \\
7093 & F-Pot-2 & 536 \\
8060 & Org-C-700 & 531 \\
\hline \hline
\end{tabular}


The top ten liquid-waste generators based on gallons/year are listed in Table 4. Those methods can be divided into four groups:

- 1. - Methods that are on both lists of top 10 liquid-waste generators per run and 10 most frequently run methods, such as method 3381.

- 2. - Methods that are only on the list of top 10 liquid-waste generators per run, such as method 3984, 8075, 8076, and 2171.

- 3. - Methods that are only on the list of the 10 most frequently run methods, such as method 3993.

- 4. - Methods that are neither on the list of the top 10 liquid-waste generators per run nor on the list of the 10 most frequently run methods.

It is apparent that in year 1998, there were only four methods that generated more than 300 gallons of liquid waste and took a share of more than $4 \%$ of the total liquid waste generated by the methods.

Table 4. The top 10 liquid waste generators in year 1998, gallons/year.

\begin{tabular}{cccc}
\hline Method \# & Method Name & LW, Gallon & LW, \% \\
\hline 3948 & Pu-Filt-1 & 4,414 & 49.89 \\
3993 & Gamma Spectrometry & 674 & 7.62 \\
8076 & TKN-color-1 & 558 & 6.31 \\
3381 & SR-Radio-1 & 365 & 4.13 \\
2171 & X-ray Fluorescence - Cl & 93 & 1.05 \\
8204 & Anions-EPA-1 & 84 & 0.95 \\
8202 & Anions-EPA-1 & 73 & 0.82 \\
8075 & TKN-color-1 & 68 & 0.76 \\
8205 & Anions-EPA-1 & 64 & 0.73 \\
8203 & Anions-EPA-1 & 55 & 0.62 \\
\hline \hline
\end{tabular}

To further focus our effort on liquid waste elimination, the detailed information of the top five waste generating methods based on total volume generated is shown in Table 5. Figure 2 shows a comparison of the top five waste generating methods in 1997 and 1998. From table 5, it can seen that these five methods totaled about $70 \%$ of the liquid waste generated. Method 3948 generated about $50 \%$ of the ALD methods waste. If we can eliminate or significantly reduce the liquid waste generated by these methods, we can reach our liquid waste control goal.

The volume of waste (8551 gallons), determined by the methods database, does not equal the remaining waste volume left after subtraction of waste operations and storm water (24320 gallons [total] minus [waste operations and storm water] 5200 gallons equals 19120 gallons). If 
the methods volume, 8551 gallons is subtracted we are still left with a deficit (10569 gallons). Another waste source is the sink(s) often left running over night in the CPP-602 laboratories. This happens at least once a year and generates about

Table 5. The details of the five top liquid waste generators in year 1998.

\begin{tabular}{cccl}
\hline Method \# & LW, Gallon & LW \% & \multicolumn{1}{c}{ Method Description } \\
\hline 3948 & 4,414 & $49.89 \%$ & $\begin{array}{l}\text { Determination of plutonium and } \\
\text { strontium in particulate filters and other } \\
\text { low level samples by solid phase } \\
\text { extraction (Pu-Filt-1) }\end{array}$ \\
\hline 3993 & 674 & $7.62 \%$ & $\begin{array}{l}\text { Gamma spectrometry using the Sun } \\
\text { Sparcstation 2 }\end{array}$ \\
\hline 3076 & 558 & $6.31 \%$ & $\begin{array}{l}\text { Determination of total Kjeldahl } \\
\text { nitrogen and ammonia by nesslerization } \\
\text { of distillate (TKN-color-1) }\end{array}$ \\
\hline 381 & 365 & $4.13 \%$ & $\begin{array}{l}\text { Radiostrontium determination using } \\
\text { precipitation separation (SR-Radio-1) }\end{array}$ \\
\hline 2171 & 93 & $1.05 \%$ & $\begin{array}{l}\text { Determination of cesium/zirconium on } \\
\text { coupons by X-ray fluorescence }\end{array}$ \\
\hline Total & $\mathbf{6 , 1 0 3}$ & $\mathbf{6 8 . 9 9 \%}$ & \\
\hline \hline
\end{tabular}

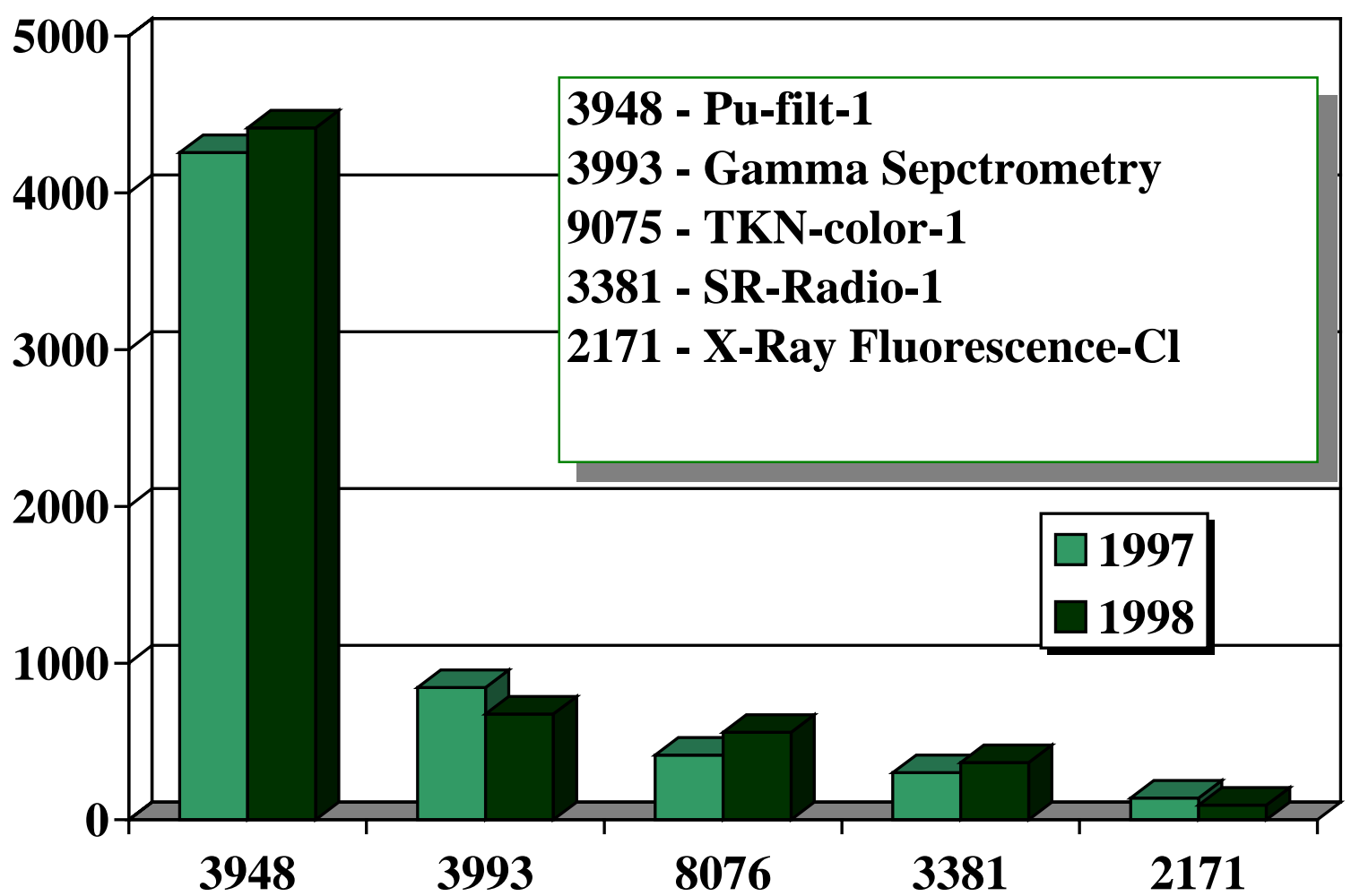

Figure 2. The liquid waste generated by the top five methods in 1997 and 1998. 
1000 gallons. This leaves us with 9569 gallons. A leak of potable water at RAL can account for some of the waste (3649 gallons). Hand washing probably accounts for a major portion of the remaining gallons of waste. Normal hand washing generates about a half a gallon of liquid waste for each time you wash. If eighteen people wash their hands 3 times a day, four days a week, forty-eight weeks a year, this equals 5184 gallons of waste. The remaining 735 gallons can be accounted for by the washing down of the RAL hot cell for a year.

Figure 3 shows the sources to the deep tanks for 1998. The ALD waste represents half of the contributors and $79 \%$ of the waste generated in 1998. Most of the ALD waste is generated by the methods. Since there are 69 methods represented in this waste, the volume per method amount doesn't seem very large. Next in volume is the hand washing. Reduction in waste generation may be possible here. The leak at RAL needs to be eliminated. Leaks shouldn't

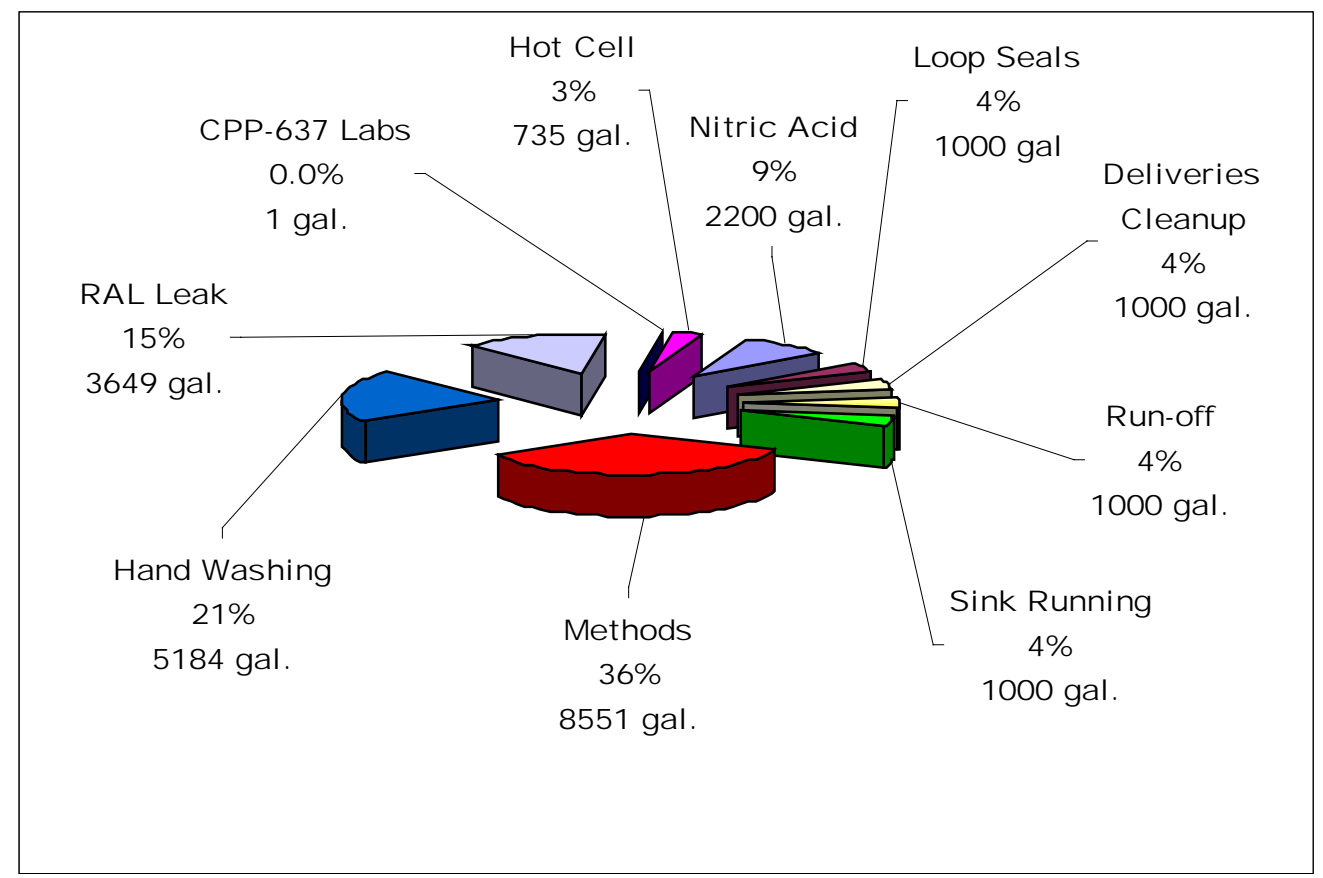

Figure 3. The waste sources to the deep tanks for 1998.

be part of the waste. Next highest is the sink left running. Many things could be done to prevent this from happening. The hot cell cleanup is the last contributor. Some items may help here. It will be looked at in a later section.

\subsection{OTHER LABS}

Many analytical methods are performed the same by all analytical laboratories because EPA and other governmental agencies require certain standardized methods and procedures to be run. The ALD is therefore faced with similar problems that other labs have. New or better ways to do chemical analysis are always evolving. Both the similarities and new discoveries prompted 
the effort to investigate what other laboratories have done to minimize their waste. Both commercial and governmental laboratories were contacted to see the diversity of waste handling practices. Eight labs sent back replies to our queries on waste minimization. Four government labs and four commercial labs gave information on waste minimization. ALD personnel have reviewed the waste minimization steps and their comments are included in the italic notes.

\subsection{Oak Ridge}

The Pollution Prevention Program at Oak Ridge provides financial and recognition incentives for identifying methods and processes for reducing or eliminating waste or providing substantial cost savings over current procedures. To date, the majority of those incentives have been handed out to the analytical chemistry organization for their waste minimization efforts.

Oak Ridge has revamped much of their laboratory equipment and has gone to using micro-scale instruments to reduce the volumes required. For example: mercury, Kjeldahl Nitrogen, and phenol analysis are all done at a micro-scale.

Labconco furnishes micro-Kjeldahl systems for use in laboratories and provided information regarding the use of micro-scale equipment that may be of general interest. Typically, the cost of the equipment is low but this is inversely proportional to the ease of use of the equipment. Going to a micro-scale increases the complexity of performing the method. It would be important to consider the success rate and ability of the analysts that will be performing the method to determine whether it would be beneficial from a time involvement perspective to introduce a micro system. Also, because of the very small sample sizes involved with microscale analysis, some accuracy is sacrificed. This is because it is relatively easy to measure low $\mathrm{NO}_{3} / \mathrm{NH}_{3}$ levels in a large quantity of sample but it is not as easy to measure low levels in a very small sample. Accuracy takes an additional hit with the micro-Kjeldahl analysis due to the fact that only a portion of the sample is distilled.

[note: Because of the inability of the system to distill the whole sample, a micro-scale Kjeldahl analysis is not good for low level nitrogen analysis (<1 ppm) such as are typical of the samples received by the INTEC Analytical Laboratory.]

Use of a Midi distillation system has helped to reduce cyanide, acid, base, and pyridine waste generation in the lab by requiring one-tenth the amount of reagents previously used by the macro method. The more efficient Midi system has reduced waste generated by $90 \%$, increased available bench space, and cut analysis time in half, consequently producing a net waste reduction of about $350 \mathrm{gal} / \mathrm{year}$.

For prepping of samples, smaller volumes have been able to be used by simply using more accurate and precise balances. For example, prepping potassium cyanide samples previously generated 1 liter of waste per week. Now, using more accurate balances, this volume has been reduced to 1 liter every 6-8 weeks.

[note: The Analytical Laboratory at INTEC already uses balances that are accurate to 5 places to keep the sample sizes to a minimum. ] 
Using standard mixtures of organic compounds rather than buying the pure compound has reduced the amount of listed waste generated. Because the organic compounds are part of a mixture, they are not considered listed waste.

[note: This is standard practice at INTEC labs.]

The Metal Prep Laboratory has modified the cleaning procedure to allow recycling of acid solutions for metal prep for ICP, ICP-MS, and GFAA. Costs savings have been realized through reduced purchase of concentrated acid and reduced treatment costs for used acids. At Y12 beginning October 5, 1994, the $10 \% \mathrm{HNO}_{3} / 10 \% \mathrm{HCl}$ acid cleaning solution was recycled into a container for reuse on routine glassware cleaning. Preparation blanks were used to prove the absence of contaminants when prepared using glassware cleaned with recycled acid. The analysis of these blanks showed no contaminants due to using recycled cleaning acid. Following initial analysis, subsequent testing showed no contamination. 156 gallons of acid waste per month were averaged during May through September of 1994. Recycling reduced the acid waste to 65 gallons for the month of October, a reduction of 91 gallons. This equates to a yearly reduction of 1,092 gallons of waste and an annual saving of $\$ 72,500$. There is an additional yearly saving of $\$ 9,600$ for $\mathrm{HNO}_{3}$ and $\mathrm{HCl}$. Other savings will come from difficult to quantify costs such as procurement of supplies, mixing acid solutions, and disposing of wastes. [note: Recycling the acids used for cleaning glassware may not be possible at the INTEC Analytical Laboratory due to the presence of trace metals and radioactivity.]

In the radiochemistry lab, sequential separations are used for the Am, U, Pu series as well as the $\mathrm{Np}$, Th series so that additional preps do not have to be done. This has reduced the waste from these methods by up to $70 \%$. It has helped to reduce the cost as well because not as much time is spent doing preps. The sequential $\mathrm{Np}$, Th method has allowed savings of $\$ 100,000 \mathrm{a}$ year.

[note: This procedure is already in use at the INTEC Analytical Laboratorys].

The number of areas in the labs that are radioactive areas has been reduced. These rad areas are primarily located only in certain hoods now. This way material can be moved in and out without making everything taken in and out become a radioactive waste.

[note: This procedure is already in use at the INTEC Analytical Laboratorys.]

All the bottles and chemicals are stored in non-radioactive areas and then only the amount needed is taken into radioactive areas. In the first shipment after the change, $\$ 20,000$ was saved. An estimate of $\$ 30,000$ in cost savings is anticipated for the next shipment scheduled.

[note: This procedure is already in use at the INTEC Analytical Laboratorys.]

Solvent dispensing stations have been set up so that the solvents can be purchased in bulk quantities (methylene chloride, acetone, and methanol). Users must bring empty containers and fill at the appropriate station. The bulk containers are returned to the vendor for refills. The waste liquid resulting from the triple rinsing of containers prior to disposal has been eliminated. [note: Safety and health concerns prevent this from being used at INTEC labs.] 
Evaporation to dryness is allowed to reduce waste volumes if there are safety issues involved. For example, solutions that contain diethyl ether are extremely volatile and for safety purposes the lab is allowed to set the container in the hood until all of the diethyl ether evaporates out. Also, when there is an acid that contains organic which can over pressurize the container, it is permissible to leave the container sitting out until the organic evaporates. However, in both of these cases and any others, special permission must first be obtained from the state.

[note: This is not permitted at the INTEC labs.]

In the radiochemistry lab, the liquid scintillation counter method was recently changed so that the scintillation cocktail is environmentally safe and does not contain any toluene or xylene. So far savings of about $\$ 5,000$ a year have been realized from this waste stream.

[note: The INTEC Analytical Laboratory changed to an environmentally safe cocktail more than 5 years ago.]

The oil and grease analysis was recently converted from using Freon 113 to using a hexane method. Extensive testing was conducted with EPA approval to show that the hexane method would provide acceptable results.

Using an automatic digestion system (A301), the laboratory was able to reduce the volume of acid used per digestion from $100 \mathrm{ml}$ to $40 \mathrm{ml}$ as well as reducing the amount of acid released to the environment by the conventional digestion method from 5-10 $\mathrm{ml}$ to almost none.

The Gilson ASPEC XL Solid Phase Extraction System has enabled a 50\% reduction of acid waste from conditioning columns in the determination of radioisotopes in samples. The system delivers acid in low pressures to the columns, resulting in more efficient use of acid and less exposure to workers. Success was obtained in analyzing for uranium, technetium, thorium, Am-241, Sr-90, and Pu-238/239.

[note: INTEC radiochemistry uses the same instrument.]

Ion chromatography instruments were changed to utilize new microbore technology. This has reduced the amount of solutions needed to maintain continuous flow through the instrument's separation column. In addition, two new state-of-the-art detectors with selfregenerating suppressors have further reduced the amount of acid reagent needed and the amount of sulfuric acid waste generated. The amount of reagent pumped through the instrument was reduced from $2 \mathrm{ml} / \mathrm{min}$ to $0.5 \mathrm{ml} / \mathrm{min}$ and the waste from each instrument was reduced from 4 $\mathrm{L} /$ day to less than $1 \mathrm{~L} /$ day (a total reduction of $235 \mathrm{gal}$. / yr.).

[note: Special analysis is going to be looking at this in the future.]

The volume of sodium carbonate standard solution used during titration procedures was reduced. Prior to implementing this change in procedure, $950 \mathrm{ml}$ of stock solution $(0.05 \mathrm{~N})$ was discarded each week, and $450 \mathrm{ml}$ of working solution $(0.005 \mathrm{~N})$ was discarded each working day. The alkalinity process was significantly improved through the use of an auto-titrator. The lab now makes use of $1 \mathrm{~L}$ of stock solution and uses $100 \mathrm{ml}$ per analytical run. All of the stock solution is consumed and discarded as waste only after use in the analytical process.

[note: Smaller sample sizes and auto-titrators are used at INTEC.] 
Performing metals analyses on waste oils destined for the TSCA Incinerator are creating PCB- and RCRA- contaminated acid wastes. The lab developed a new way to digest the oil samples without contaminating them with certain acids by using a mixture of $50 \%$ nitric acid and $50 \%$ hydrochloric acid heated to $300^{\circ} \mathrm{F}$. The acid mixture is reused until it can no longer solubilize the metals and then neutralized with Micro-soap. The lab has eliminated the generation of approximately 5 gal/week of PCB-contaminated acids and has reduced the generation of RCRA-contaminated acids from approximately $500 \mathrm{ml} /$ day to only $5 \mathrm{ml} /$ day. [note: This is not applicable at INTEC.]

A glow discharge mass spectrometry instrument was purchased in 1992 at a cost of about $\$ 460,000$ and was purchased mainly as an upgrade for the old instrument. The new instrument does not require photographic plates and developing solutions, which eliminates $67 \%$ of the corrosive waste generated by the process. The new instrument takes about half as much time to run a sample. A cost saving of $\$ 27$ per sample is realized by the elimination of the photographic plate needed to analyze the sample by the old technique.

[note: The photographic plate technique is not used at INTEC any more.]

An instrument capable of identifying, quantifying, and extracting organics in aqueous samples, without the use of organic solvents was procured to replace the current method. The capability of not using an organic solvent for extraction is important in that no solvent purchases are necessary, no hazardous waste is generated, no waste is disposed of, and costs per analyses are lessened due to greater sample throughput. Solid Phase Microextraction (SPME) GC/MS is a combination of two instruments to analyze analytes in solid, aqueous, and gaseous samples. [note: The instrument and technique described is not used at INTEC.]

A ten year old Manual Cold Vapor AA was being used to analyze mercury samples. The instrument continually needed maintenance due to age problems. A new automated analyzer was procured to cut down the need for maintenance. It also reduces the reagent RCRA lab waste by $94 \%$, saves time on sample preparation and analysis, eliminates the need for complete reanalysis of the samples, and eliminates the need for dishwashers.

[note: INTEC labs replaced most of their cold vapor mercury systems too.]

Samples submitted for groundwater analysis (ion chromatography analysis) are being reduced from $250 \mathrm{ml}$ to $125 \mathrm{ml}$. Only $25 \mathrm{ml}$ of sample is required for each determination, and $125 \mathrm{ml}$ still allows for a large safety margin (in case of reruns, etc.). This project will require revision of the Groundwater Program sampling procedure.

[note: INTEC currently practices this policy.]

A Cetac MCN 6000 autosampler is being purchased to replace the Inductively Coupled Plasma-Mass Spectrometry (ICP-MS) autosampler currently in use. Because the new autosampler is $100 \%$ efficient, it will require less sample material and less acid rinsate to achieve the same analytical results.

A project is planned to increase the sensitivity of the thermal ionization mass spectrometer (TIMS) used for the analysis of total uranium and isotopic uranium present in low concentrations in waste materials. The existing system requires larger sample size and 
significant technician time. Modification of the system would reduce sample size significantly $(50 \%)$, decrease technician time by approximately $60 \%$, reduce raw materials used, and increase capacity without addition of personnel or equipment by allowing unattended off-shift operation of the TIMS.

Based on the various waste minimization practices implemented, a cost saving of $\$ 1.1$ million was realized in 1996. In 1997, calculations show savings of $\$ 195,000$ due to waste minimization practices and activities.

\subsection{Hanford (PNNL)}

At Hanford's laboratory most of the samples run are radioactively contaminated, so the sample sizes are kept quite small. The lab does not normally cook up huge quantities of material like an environmental lab would, so there aren't the quantities of sample prep leftovers that there might otherwise be.

[note: INTEC currently practices this policy.]

Much of the chemistry used has been designed to make as little waste as possible and to make the waste as benign as possible. The chemical sewer or radioactive sewer is no longer available for disposal at these labs. The waste is collected in jugs, so it must be chemically stable. The lab pays for disposal by the jug, so the waste fractions are kept as small as the chemistry will permit.

[note: INTEC labs have practiced the same policy to reduce wastes and still have their drains.]

Most of the leftover sample is from making dilutions. Samples often have to be diluted substantially to get a final prep low enough in radioactivity to count. The sample leftovers are disposed of as $2 \mathrm{M}$ nitric acid radioactive waste.

[note: INTEC currently practices this policy.]

Most of the chemical separations use $\mathrm{HCl}$ and $\mathrm{HNO}_{3}$. Not much else goes in the waste jugs. The lab is planning on replacing one particular actinide separation that calls for ascorbic acid mixed with $2 \mathrm{M}$ nitric acid because that combination of organic and acid can pressurize a waste jug.

[note: INTEC currently practices this policy.]

Recently a switch was made from a fluorometric uranium analysis to a kinetic phosphorescence uranium analysis, partly because it generates half as much waste. The phosphorescence analysis works well on water samples.

[note: This type of analytical technique would not work effectively on the samples that are received at the INTEC Analytical Laboratory because even just a trace of organics will quench the phosphorescence of the samples.]

About one year ago, the procedure for mounting actinides for alpha spectroscopy was optimized resulting in a reduction in the volume of $\mathrm{HF}-\mathrm{HCl}$ waste by half, as well as achieving improved spectral resolution. 
Attempts have been made to treat the waste onsite, but progress has been slow. Most of the waste streams can be treated by distillation to remove the acids, which then could be simply neutralized and disposed of as non-rad waste. One waste stream could be deionized. There is only one non-radioactive acid waste stream, and that is simply neutralized to make it nonhazardous.

[note: Work on treatment is slow here also. Neutralization is not permitted.]

\subsection{Savannah River}

Liquids generated from the laboratory analyses at the Savannah River site are actually sent back to the canyon operation process for acid and water recovery. Thus, RCRA materials resulting from analytical measurements can be discarded as liquid byproduct and are out of the regulatory loop. However, they also take the approach that if they can find substitutes for these potential RCRA hazardous reagents, they do. Thus, they have eliminated the use of most of the RCRA F001 and F002 halogenated solvents and have almost eliminated the use of F003 solvents, which they had used quite extensively. These substitutes have not generated a lot of cost savings, other than the reduced potential of generating mixed waste. Generally, the nonradioactive analytical liquids are sent to the same radioactive liquid byproduct tank for water/acid recovery.

[note: The waste at INTEC labs is sent to an evaporator and acid recovery system also.]

Other characteristically hazardous materials (mainly $\mathrm{Cr}$ and some Ba reagents) do go down the drain as analytical byproducts, but a study performed on the resulting liquid shows this liquid to be generally below regulatory levels.

They have a chemical management system that incorporates a chemical review and "colored label" designation. Thus, any analytical chemical, reagent, or commercial chemical product (i.e. cleaning solutions, paint, etc.) that comes into the building has to have an approved review sheet indicating possible RCRA ingredients and the proper chemical storage "color coded" label. If the material has the potential to be RCRA hazardous, a substitute is sought. If no substitute is available, the facility manager must approve of its use in the building.

[note: A similar review system has been in place here at ITEC for years.]

A chemical management system was instituted. A "blue dot" identification system is used on analytical chemicals, reagents, and commercial chemical products that indicates that if the contents will need to be discarded as RCRA hazardous or mixed waste. This has encouraged limiting or controlling amounts of chemicals into radiological control areas and using all of the contents for its intended purpose, i.e. not discarding partially empty containers.

[note: The INTEC Analytical Laboratories have already instituted the practice of labeling each chemical that is received with pertinent information relating to its ultimate disposal. This information is also placed on make-up solutions from quality control.] 
Chemicals and chemical reagents (being sole active ingredients) of $U$ and $P$ listed materials also have a blue dot designation and, if declared to be waste, have to be managed as hazardous or mixed waste. Again, this encourages makeup and usage of only the volume expected for analysis and discourages discarding unused solutions.

[note: INTEC currently practices this policy.]

Contents of any blue dot labeled containers, when declared waste, are managed as hazardous waste, usually in satellite areas. Due to the nature of cross-contamination issues when handling radioactive materials, many of the items used in the analytical procedures are disposable. Thus, liquid wastes are generally a result of the analytical method. Again, during procedure development and/or method review, review for potential waste minimization (both solid and liquid) is one of the items that is part of a checklist. This review has helped in keeping waste volumes in the forefront of the analytical methods.

[note: This is the same at INTEC Labs.]

Presently the analytical liquid byproducts are collected in 2-liter container which is dumped into the liquid byproduct tank after certain analyses are performed. A composite aliquot is taken for waste characterization purposes.

[note: Segregation of wastes based on compatibility is practiced extensively at INTEC labs.]

\subsection{General Engineering Laboratory}

An evaporation unit is used that handles most of the C-14, Sr-90, H-3, Co-60, etc. that are tied up in their wastes. A sample screening is run for tritium. If there is none found, then they can reduce the waste down by distillation, which essentially bakes the waste down to dirt. Evaporation is only taken to a certain point to avoid causing the waste to be concidered mixed hazardous waste.

[note: This is not permitted at INTEC labs.]

A sample collection area is set up in order to segregate radioactive from non-radioactive waste by containers. Different containers are used for different waste types, for example, one container is used for radioactive, one for oils, one for solvents, and etc.

[note: Segregation of wastes based on compatibility is practiced extensively at INTEC labs.]

Freon is used for oil and grease testing. A distillation rig is utilized to run the waste through and then recycle all of the rinsates and Freon back through the process. They are working on a distillation rig that is a temperature gradient column for recycling methylene chloride but this is not in operation yet.

[note: INTEC Analytical Laboratory purchased a unit similar to this a few years ago for $\$ 4,000$ to recycle methylene chloride. However, they are not allowed to use it under the terms of the existing waste permits.]

Precipitation reactions are created in the various sample collection drums. For example, some containers contain silver nitrate. A salt is put into the drum in order to precipitate the silver out. The precipitate is pumped out and put in a separate drum that is labeled as the silver drum. The silver drum can then be disposed of as hazardous waste and the rest of the drum where the 
silver came from can be disposed of as regular radioactive wastewater. It is estimated that to dispose of the whole drum, with the silver nitrate in it, would cost about $\$ 5,000-6,000$. By getting the silver out, it only costs about $\$ 1,700$ to dispose of the drum. All of the drums are neutralized prior to shipment.

[note: Neutralization is not permitted at INTEC.]

A profiling system is performed on each type of waste that is collected. A few drums are sampled to find out the average activity of the drum, then that is listed for all of the additional drums with similar types of waste rather than sampling every single drum. Dry waste is placed in boxes because these are lighter than metal drums and this reduces costs since disposal costs are by the pound. A crusher is used for metal drums that can reduce the volume by up to 12 times.

For non-radioactive waste, a letter was sent to the people who control the sewer inquiring what the minimum levels for every possible contaminant were for sending wastes to the sewer system. Once a letter was received outlining the acceptable levels, the drums are tested to see if it is below these levels. The waste is neutralized and put directly into the sewer if it is below the regulatory limits.

[note: Most of this is not applicable due to the radioactivity present in the waste at INTEC.]

\subsection{RECRA Labnet in Philadelphia}

RECRA Labnet uses an aqueous phase separation unit (APSU), which amounts to a pot evaporator. Their biggest volume waste stream and the one most difficult to deal with is aqueous acidic waste that typically does not have real high levels but above RCRA levels of the metals. Under EPA exemption 268.A74, waste can be treated onsite provided the EPA is notified within 30 days. The acid waste is neutralized prior to placing it in the APSU. The unit is composed of a custom-made 30 gallon $1 / 2$ " wall Pyrex beaker that is about 18" in diameter which fits inside a 55 gallon drum. Eight to ten inches of sand is placed in the bottom of the 55-gallon drum. The 30gallon beaker is placed inside the 55-gallon drum and the annulus is filled with sand. The sand serves as a heat transmitter. The drum is fitted with two drum collars. The drum is then suspended on a grate on top of a well, made of cinderblocks, and put inside a 4-ft fume hood. This provides triple containment between the Pyrex beaker, the drum, and the fume hood. Before the system was put in place about 200-300 gallons of waste had been backlogged, which took about 8 months to finally work off using the APSU. Now, with the system fully in place and the backlog worked off, the system is more than capable of handling the waste generation from daily operations. The process results in a residue that is solidified using a product acquired from Delware Custom 2 located near State College in Pennsylvania. This product is basically portland cement, dirt, the mixture from the drum and "heavy water" which is basically sodium silicate with a density of about 1.4. About a bag and a half of cement per drum is used with a gallon of the sodium silicate poured in and mixed. Within about 5 minutes the liquid is solidified. The APSU system handles both aqueous based waste and mixed waste solids that can be tied up in the solidification process. RECRA Labnet had a contract in place with NSSI in Texas for 
treatment of their aqueous waste plus 4 drums of solid material for $\$ 150,000$. The cost for treating the same amount of waste onsite with the APSU unit is less than $\$ 40,000$, which includes capital expenditures.

[note: An aqueous phase separation unit is not be feasible at the INTEC Analytical Laboratory.]

Managing to remove codes based on additional analysis has effected additional waste minimization. Using EPA guidance documents, they were able to justify removing the F code from some of their waste streams as well as other codes as well. The same volume of waste was generated but, using this guidance, less of that volume of waste now carried a listed waste code.

\subsection{Babcock \& Wilcox}

Changing procedures is the primary thing that has been done to minimize waste generated from laboratory activities. The biggest reduction came from switching from solid phase extraction to ion exchange separations using EiChroM resins, etc.

[note: Ion exchange separation using EiChroM resins is already being performed in the Radiochemistry Lab at INTEC.]

Using smaller sample sizes, when applicable, has reduced the amount of solvents used. Using a liquid scintillation counter with a low background has also helped to achieve more accurate results.

[note: Smaller sample sizes are already being used at INTEC.]

\subsection{Paragon}

Disposable containers (Marinelli beakers) are not reused for gamma spectrometry and non-destructive examination methods. A liter Marinelli beaker costs about \$1.50-2 per unit. Disposing of the container after use versus cleaning the glassware and reusing also reduces the potential of cross-contamination.

[note: Radiochemistry uses the above technique for the same reasons.]

Perchloric acid is not used for a digestion. Instead, a $\mathrm{HNO}_{3} / \mathrm{HCl}$ digestion is used followed by a nitric acid preparation then elution through an ion exchange column (EiChroM). This generates much less resin per column as well as generating less acid waste. A batch of 20 samples produces an acid waste volume of 2-4 L.

[note: Perchloric acid is being phased out at INTEC.]

On graphite furnace atomic absorption spectroscopy, an attempt is made to minimize the sample volume. The number of runs performed is also kept to a minimum. Quality control (QC) is performed on samples that aren't radioactive to reduce the amount of radioactive waste generated. The effluent is segregated from the instrument to make sure the instrument is not contaminated by contact with a radioactive effluent. Most of the work is done on an ICP trace instrument that can analyze for all of the metals simultaneously, hence generating less waste. 
ICP generates fairly small volumes of waste. Segregation is practiced to keep the amount of radioactive waste generated to a minimum. Typically only $5 \mathrm{ml}$ of waste is generated per run. An attempt is made to organize the analyses so that the radioactive samples are analyzed consecutively so the waste can be seperated. It is important to ensure that the amount of sample that is prepared is all that's needed to avoid generating large quantities of preparation waste that is never used.

[note: Spectrochemistry at INTEC uses the segregation technique mentioned above.]

Before proceeding, the procedures are examined carefully to determine exactly what's required. The sample preparation is structured so that there is enough volume to do the analysis it but not much more than that.

[note: INTEC currently practices this policy.]

For radiostrontium analysis, ion exchange methodology (EiChroM) is used. They are careful to only ask for the sample volume that is absolutely needed from the samplers to ensure that they don't have a lot of left over sample.

[note: This reduced sample procedure is practiced at INTEC radiochemistry lab too.]

Most of the methods specify the sample size that should be used. However, if the required detection limit is achieved, then one can get away with using smaller samples than is called for. When the amount of sample coming in is limited to a predetermined amount, then it is possible to limit the amount of waste generated. For example, if a method calls for dissolving 1 gram of sample in $50 \mathrm{ml}$ of solvent but the procedure only requires $10 \mathrm{ml}$ of final sample, perhaps dissolving 0.5 gram of sample in $25 \mathrm{ml}$ of solvent would be more appropriate. If sample homogeneity is an issue then it may not be possible to reduce the sample. One way of reducing the potential of generating excess waste would be to pre-screen for alpha-beta when a sample is suspected of being contaminated with plutonium to get a good feel for what the levels of contamination will be. An internal tracer is used and a ratio is taken that tells how good the separation was. If the separation is good on the pre-screen, then it may be possible to digest a smaller sample. If the alpha-beta count reads 5,000 disintegration per minute then one could use more of the tracer or digest less of the sample or both. This pre-screening helps to avoid the potential of having to prepare the sample again and/or redo all the work .

[note: This same reduction is done at INTEC when possible.]

Ion chromatography for anions is similar to the sample preparations for ICP. The sample preparations are minimized as well as trying to use instruments that have a lower detection limit. [note: This same reduction is done at INTEC when possible.]

Cleaning of glassware generates significant quantities of waste. Keeping the glassware to a minimum and using primarily disposable materials can reduce this. Keeping the glassware washings to a minimum is important both from a labor standpoint as well as the potential crosscontamination issues.

[note: This same reduction is done at INTEC.]

Seventy to eighty percent of the waste problem could be resolved by minimizing the amount of sample preparation volume and identifying what the minimum amount of sample 
needed is for any given method. It's important to ensure that the lab does not get in more sample volume than what is absolutely needed.

[note: This is practiced at INTEC.]

\subsection{Argonne National Laboratory - East}

Laboratory personnel at ANL-E performed a study to evaluate various methods for reducing secondary wastes in the inorganic, organic, and radiological analytical areas. They were able to successfully demonstrate that wastes can be reduced using alternate methods, techniques, and technologies without sacrificing accuracy or precision.

Inductively coupled plasma (ICP) emission spectroscopy and ICP-mass spectroscopy (ICP-MS) are used routinely in inorganic analyses. One prominent weakness of this method is sample introduction inefficiency due to the fact that normal pneumatic nebulizers, i.e., glass concentric types, utilize only $1-10 \%$ of the sample uptake. The remaining portion of the sample goes directly to laboratory waste, creating a waste stream that is considered corrosive and in some cases toxic and/or radioactive. ANL-E personnel compared the performance of a direct injection nebulizer in combination with flow injection (FI-DIN) to a commercial ICP-MS instrument that uses continuous pneumatic nebulization (CPN) using aqueous samples. They discovered that $7.1 \mathrm{ml}$ of waste were produced per sample using CPN while only $3.4 \mathrm{ml}$ of waste was generated using FI-DIN. Most of the FI-DIN waste was a result of overfilling the injection loop and dead volume between the sample and the injection loop. The CPN analysis required 7.5 minutes per sample versus only 5 minutes per sample using FI-DIN. The saving in time was due solely to the reduced rinsing time. ANL-E personnel feel that further savings in waste and time could have been realized by using more efficient flow injection procedures. A comparison of the background concentrations, instrument detection limits, and elemental concentrations suggest that FI-DIN could be used interchangeably with CPN for elemental determinations by ICP-MS. [note: INTEC nebulizers have been chosen for their low flow rates $(0.8-1.5 \mathrm{~mL}$. / min.) and more importantly that they don't plug in the high salt conditions.]

Soil dissolution for radiochemical analyses traditionally uses the technique of high temperature fusion and prolonged acid digestion, both of which are time consuming and generate large quantities of secondary waste and fume hood emissions. New microwave systems, that use closed vessels, can withstand pressures up to 1,500 psi and are thus able to accommodate larger sample sizes. The ANL-E personnel achieved shorter processing times and reliable sample digestion with a dramatic reduction in secondary wastes. The performance of a high-pressure microwave system was compared to gross $\alpha / \beta$ measurements using the traditional procedure of a hotplate for digestion followed by repetitive acid treatment. The microwave procedure demonstrated good reproducibility and low blank values. The acid volumes required for the microwave procedure were a factor of 9 lower than the traditional hotplate method, the analyst time for sample processing was a factor of 2.5 lower, and the sample turnaround time was a factor of 16 lower. Since reactivity increases as pressure increases, the high-pressure microwave system may make it possible to use the alternative, nonhazardous solvents for leaching certain contaminants from soils for analysis. ANL-E personnel also investigated the replacement of strong, corrosive acids with milder, nonhazardous complexing agents for removing plutonium from soils. Although these agents have been successfully used for the extraction of contaminants 
such as plutonium, the reagents fail to totally break down the sample matrix and are, therefore, not applicable to constituents such as $\mathrm{U}$ and Th.

The prescribed EPA method for extracting semivolatile organic compounds (SVOC) from solid samples typically use up to $300 \mathrm{ml}$ of hazardous solvents. With microwave assisted extraction (MAE), the amount of solvent required could potentially be reduced to 30-50 ml. Efficiencies using MAE for extraction compared favorably, in most cases, with conventional extraction techniques outlined in SW-846 Method 8270B with the added benefit of reduced solvent usage. Recoveries of some of the more volatile SVOCs were low and indicate a potential sample stability problem. A number of compounds, particularly strongly polar materials such as benzoic acid and some amines and pyridines, were not extracted efficiently. However, this inefficiency is observed with both MAE and the traditional extraction techniques. Overall, recoveries of SVOCs from soil, sediment, and sludge using MAE compared well with recoveries using traditional extraction techniques and the solvent usage and waste produced were decreased by an order of magnitude using MAE.

[note: MAE is used at INTEC with the same results.]

\subsection{DISCUSSIONS OF RESULTS}

The database has shown that most of the analytical waste is generated by one method. Radiochemistry has come up with an alternative to this method (Pu-Filt-1). Switching to this method will reduce the waste generated by this method by $99.8 \%$. This is a change from $49.89 \%$ to $0.001 \%$ of the total ALD waste. The method previously used the perchloric acid hood and generated about 1000 liters of waste each time it is run. This switch will save about 4400 gallons of water to the deep tanks. The new method is scheduled to be in service on the June stack filters (performed in July).

The conductivity analysis was the next area that could have a sizable impact. The method uses standards, samples, and cleaning rinses that generate significant waste. Sample size was an area where a reduction looked promising. A new electrode was purchased with a temperature probe built into the body of the probe. This could reduce the sample volume required by about one quarter. The cost to reduce the container size ended up being one of the limiting factors. The cost of the two ounce plastic bottles (60 milliliters) is $\$ 0.58$. The cost of a plastic test tube (50 milliliters) is $\$ 2.38$. This means that you can buy 4 two ounce bottles for the price of one test tube. The waste reduction problem is further complicated by the fact that the lab gets more sample volume than needed for conductivity on most samples. This means that reducing the sample volume on conductivity analysis is not going to effect a waste reduction in the sample because the sample excess is dumped to PEW anyway. This negates any gain we made in volume needed for sample analyses.

Rinsing was by far the biggest contributor to the PEW from the methods. 79 percent of the waste generated from analysis was from rinsing. A little amount of saving from many of the methods would work out to be a significant volume in a year. Total Kjeltec Nitrogen (TKN) could reduce rinse water generation by recycling the final rinse on the first piece of glassware 
being cleaned as a wash on the next glassware. There may be even a time saving by doing it this way. The individual analysts must evaluate each of their methods to determine which methods can be improved by changing their rinsing sequences.

Beta plates are cleaned before they are used. All the waste is disposed of to PEW due to the chemical content. These plates could be cleaned in a non-radioactive area using a different cleaner and the waste sent to a non-radioactive waste area. A small savings of thirty-eight gallons would be realized. This involves switching from nitric acid to a detergent to clean off the film of oil on the plates. The rest of the cleaning procedure would be the same as stated in the method. Maybe the plates could be wiped clean and then no liquid waste would be generated.

Sample volumes can be reduced. Operations personnel, who send most of the samples to RAL, said that if notified of the sample volume requirements, a smaller volume could be sampled. The change, if permanent, can be put into their procedures. Many of the samples have volume requirements dictated by other groups (EPA, RCRA, State of Idaho, etc.). The sample volumes must not be changed without concurrence from each group.

One of the first large generation items, identified by waste operations as a generator of waste, that could be reduced are sinks left running in the analytical labs. At least once a year, a sink is left on in the analytical laboratories in CPP-602 (usually a hood sink because it is harder to hear that it is running). This generates about a thousand gallons of water to the deep tanks. Options to solve this problem are: administrative controls and physical controls. Administrative controls vary from reminders sent out to the lab personnel to procedures written to prevent the occurrence(s). The supervisors and manager will have to determine what is necessary in this category. Physical controls can be anything that physically reduces the chance of having a sink left on. Some of the possible fixes are foot pedals, water flow timers (like used on garden hoses), timed valves (faucet stays on a short amount of time), and electronic sensor faucets. Here the cost versus benefit and budget determines if a physical control can be implemented. The waste costs about $\$ 4.26$ a gallon to process ${ }^{2}$. If 1000 gallons of waste were saved from going to the deep tanks the value works out to be $\$ 4260$ saved.

The ICP at RAL runs 24 hours per day. It is on reduced flow when unattended. The ICP uses $3 \%$ nitric acid at a flow rate of one milliliter per minute when attended and about one-third of a milliliter per minute when not attended. If, during the unattended time, the ICP flow is switched from the 3\% nitric acid to water, 2.63 liters of nitric acid would be saved per year. This is not possible at the present time because boron and antimony hang up in the tubing. To help reduce this hang up of chemicals, they run the acid all the time. When sample composition changes, the switch to water will be more practical.

Leaks (like from the back flow prevention valves at RAL) have amounted to about ten gallons a day going to the deep tanks. The RAL back flow prevention valve leaks are from potable water sources to the safety showers. Potable water increases chloride content of the waste. The chloride content increases the need for nitric acid in the evaporation process to keep the stainless steel passivated, thereby increasing the corrosives added to the waste. 


\subsection{RECOMMENDATIONS}

The implementation of the new method to do stack filters, as soon as possible, is the first recommendation. This one method represents about half the waste generated by analytical methods. The sooner it is eliminated, the bigger the waste reduction. The method is presently scheduled to be on line in July of 1999.

The next recommendation is that as much hand washing as is possible be done in the bathrooms. More, rather than less, hand washing is probably in order, but to reduce waste to the radioactive waste system as much hand washing as possible should be done in the bathrooms. It is recommended that the times personnel you go on breaks, to lunch, and/or when they quit for the day, that the hand washing be done in the bathroom to reduce waste to the deep tanks. This is by no means meant to bypass any safety or radiological requirements. This is only meant to reduce waste generation when possible to the radioactive liquid waste system.

The leaks from the (potable water) back flow prevention valves at RAL are the next largest source. These valves leak about 10 gallons a day to the deep tanks. The leaks should be hard piped to a sanitary sewer on the cold side of the RAL. This diversion will save about 3650 gallons of high chloride waste from the deep tanks. A work order is in the process of being written to work on correcting this problem by Carl Lundholm but management support may be needed.

One problem with leaving a sink running is that the person that did it never intended for it to happen. A reminder or procedure won't necessarily stop it from happening again. The need is for positive controls; a faucet that turns off after a certain time, foot pedals, electronic sensor faucets, and timers. Any of these possibilities could be used in one location or another. The money to buy and install the changes is one of the problems. The hoods in the CPP-602 200 labs are prime candidates for the water timers or foot pedals attached so that the faucets are not left running. Another faucet that needs one of these fixes is in the CPP-684 hood 920 (flossy hood).

Rinsing labware is a major contributor to waste. Any reduction in rinse water usage would help. Reusing rinses is a possible way to reduce waste generation. The final rinse on washing a piece of labware could be used as the wash or first rinse on the next piece. In this way contamination won't be a problem and the total waste volume is reduced. TKN is a prime candidate for this reduction. The reuse of rinsate will be tried on the next cleanup from this method at the end of July 1999.

The water wash system for cleanup of the RAL hot cell should have flow restrictors placed in the system so that waste generation is kept to a minimum when cleaning.

The Reducing sample volumes needs to be evaluated on an individual basis. This should be done with the analysis requestor so that arrangements can be made to return the samples or to have a smaller sample provided. Conductivity is a method that excess sample is usually provided. The attempt to reduce sample size, to reduce waste generated, is negated with the excess sample volumes that are placed in the PEW. With conductivity cost may over ride waste 
reduction. The low cost of a 2.0 ounce bottle $(\$ 0.58)$ seems to over ride the switch to the smaller and more expensive $50 \mathrm{~mL}$ plastic test tub (\$2.40). This cost difference, along with the excess sample being delivered, is not sufficient cause to use the test tubes.

The ICP at RAL runs 24 hours per day. If the ICP operated on water during the unattended shifts, it would save a little more than a $2 \frac{1}{2} \mathrm{~L}$ bottle of concentrated nitric acid a year. This can be accomplished as soon as the labs are no longer running antimony and boron. These two elements require the ICP to be run on nitric acid.

Beta planchets come to the lab with a small mount of oil and dirt on them from the manufacturing process. They should be cleaned in a clean (non-radioactive) area and the cleaning solution put to the sanitary sewer. They could be easily cleaned with detergent and water, and then dried or by some other cleaning process that wouldn't generate any waste to the PEW. They could be wiped clean which generates no liquid waste.

The last recommendation is that a separate fund for waste reduction improvements/benefits be established to take care of the needed changes necessary to improve waste reduction. Incentives could also be paid from this fund.

\subsection{REFERENCES}

1. J. L. Tripp, et. al., INEEL Liquid Waste Management Plan, PLN-439, July 1998.

2. L. Lauerhass, to J. E. Hovinga, "Estimate of Incremental Benefit/Gallon of Tank Farm Waste Reduction," LL-01-98, August 31,1998. 